\title{
Growth hormone, acromegaly and glucose metabolism
}

\begin{abstract}
Abbreviations: GH, growth hormone; GHR, growth hormone receptor; IGF-I, insulin-like growth factor-I; GLUT-I, glucose transporter I; EGP, endogenous glucose production; FPG, fasting plasma glucose; IGT, impaired glucose tolerance; DM, diabetes mellitus; IR, insulin resistant; SSA, somatostatin analogues; GHRA, growth hormone receptor antagonists
\end{abstract}

\section{Editorial}

Growth hormone $(\mathrm{GH})$, as its name suggests, is implicated in postnatal growth. It is also used in replacement therapy for GH deficient children to induce linear growth. ${ }^{1}$ Indeed, it is well proven that pituitary GH deficiency or a defect in tissue GH receptor (GHR), result in dwarfism, whereas an excess of pituitary GH secretion results in gigantism in juveniles, or acromegaly in adults. The $\mathrm{GH}$ and insulin-like growth factor-I (IGF-I) axis is not only involved in the regulation of somatic growth, but also in glucose metabolism. During fasting and stress, GH secretion is increased and these conditions may be viewed as the natural metabolic domain for $\mathrm{GH}$ action. $\mathrm{GH}$ decreases glucose uptake in adipose tissue and regulates the glucose transporter I (GLUT-I) in adipose-tissue-derived cell lines. ${ }^{2}$ GH may antagonize adipocyte insulin action. At hepatic level, GH increases glycogenolysis, thereby increasing endogenous glucose production (EGP), which could possibly be as a result of insulin antagonism. GH-deficient children have reduced fasting plasma glucose (FPG) levels, impaired glucose tolerance (IGT), and increased insulin sensitivity due to increased glucose utilization and diminished EGP. ${ }^{3,4}$ GH replacement increase FPG, insulin levels and EGP. ${ }^{4}$ GH-deficient adults have elevated fasting insulin levels and show a positive correlation between fasting plasma insulin and both fat mass and waist girth, suggesting the presence of insulin resistance. GH replacement initially increases insulin resistance even more, during the first 1-6weeks of therapy, but long-term studies suggest that this subsequently reverts to unchanged insulin-sensitivity. ${ }^{5}$ Developmental models of GH deficiency and excess indicate that GH is positively associated with $\beta$-cell mass. The reduction in GH levels observed with age and weight gain may contribute to the age-related decline in pancreatic $\beta$-cell function. Humans with long-term adult-onset GH deficiency, or with developmental isolated GHD, show IGT, ${ }^{6,7}$ and may have an increase prevalence to diabetes mellitus (DM). ${ }^{8}$

IGT and DM are both severe complications that frequently affect acromegalic patients. In fact, some studies have reported a direct correlation between circulating GH plasma levels and the degree of glucose intolerance. ${ }^{9}$ The presence of both pancreatic $\beta$-cell dysfunction and insulin resistance has been suggested in the pathogenesis of glucose intolerance in acromegaly. In a sample of 98 acromegalics, 17 with diabetes and 39 with newly diagnosed disturbances of glucose metabolism, we demonstrated that diabetics were older, heavier and more insulin resistant (higher HOMA IR) and that they had lower insulin levels (evaluated by HOMA $\beta$ ), and showed a significant correlation between mean GH levels, IGF1 and insulin resistance. ${ }^{10}$ Risk factors for diabetes in acromegaly are: high GH/IGF-1 serum levels, older age, longer duration of the

\author{
Volume I Issue 4 - 2014
}

\author{
Davide Carvalho, Claudia Nogueira, Paula \\ Freitas \\ Department of Endocrinology, University of Porto, Portugal
}

Correspondence: Davide Carvalho, Department of Endocrinology, Diabetes and Metabolism, Center Hospital S. Joao, Faculty of Medicine, University of Porto, Portugal, Email davideccarvalho@gmail.com

Received: September 19, 2014 | Published: September 20, 2014

disease, a family history of DM and concomitant hypertension. Acromegaly surgical management is associated with improvements in glucose disturbances. The first somatostatin analogues (SSA) used - Lanreotide and Octreotide - had a marginal impact on glucose metabolism. ${ }^{11}$ No modification of fasting glucose, HbA1c and a small change in glucose under OGTT and fasting insulin were observed. ${ }^{11}$ No correlation was observed between biochemical control of acromegaly and glycometabolic parameters during SSA treatment. These SSA act mainly in somatostatin receptor type 2 (ssrt2). Pasireotide, a multireceptor SSA, is promising for future acromegaly management, as it is more efficient when compared with octreotide, on account of a broad spectrum of ssrt action -it acts at ssrt2 and ssrt5 and also at sstr1 and 3, although with lower affinity. ${ }^{12,13}$ Its drawback is the evidence of a higher prevalence of glucose disturbances $(28.3 \%$ for pasireotide versus $8.3 \%$ for octreotide). In fact, the human pancreatic $\beta$ cell shows a greater presence of sstr 5 expression than ssrt2, and $\alpha$ cell has less presence of sstr2, and almost no sstr5..$^{14}$ Therefore, pasireotide inhibits insulin secretion more, and has almost no effect on glucagon secretion. ${ }^{15-17}$ Supporting this mechanistic explanation, drugs that stimulates insulin secretion and supress glucagon production, such as DPP4 inhibitors (e.g. vildagliptin) and GLP-1 analogues, induced better glycaemic control in pasireotide-treated acromegalic diabetic patients. $^{18}$

GH receptor antagonists (GHRA) are another option for controlling IGF-1 production and thus blocking GH action. Pegvisomant, the only commercially available GH antagonist, induces an improvement in acromegaly glycaemic control through the decrease of glucose and the normalization of insulin secretion. ${ }^{19}$ This effect enables one to understand the important effect of GH on hepatic and peripheral IGF1 action. Hepatic GH-induced IGF1 production is regulated by portal insulin levels, ${ }^{20}$ as insulin promotes the translocation of hepatic GHR to the surface. When portal insulin levels are high, the liver becomes GH sensitive, regardless of the cause of the increase production of insulin. In addition, portal insulin also inhibits hepatic IGFBP1 production, which may increase the bioavailability of circulating IGF1. Insulin suppression by SSA also selectively results in hepatic GH resistance, which itself decreases hepatic IGF1 production. ${ }^{20}$ Therefore, the consequent reduction in circulating IGF1 does not necessarily reflect GH activity in peripheral tissues. It thus makes sense that 
normalization of serum IGF1 levels during SSA does not necessarily imply the control of disease activity in peripheral tissues, which is a condition that Neggers coined as being "extra-hepatic acromegaly". ${ }^{21}$ This concept received support in a study in which evaluated surgically and SSA treated acromegalics. Despite normalization of IGF-1, SSAtreated patients had less suppressed GH levels and less symptom relief. ${ }^{22}$ On the other hand, GHRA, however, does not block all tissues with equally effectiveness for the actions of GH. Adipose tissue seems to require less GHRA to reduce GH actions when compared to the liver, where more GHRA is required to reduce IGF1 production. ${ }^{23}$ This could be a reason for local GHRA induced lipomatosis. In further support of this hypothesis, it was recently reported that shortterm GHRA administration in healthy subjects can suppress lipolysis, without affecting either circulating or local IGF $1 .{ }^{24}$ Accordingly, it is possible that peripheral suppression of $\mathrm{GH}$ activity is obtained prior to normalization of hepatic IGF-1 production. Therefore GHRA treated acromegalics with normal peripheral IGF-1 could have peripheral GH deficiency. ${ }^{21}$ If all this is true, then acromegalics should need higher GHRA doses to normalize IGF-1, than non-diabetic acromegalics. Recently, this was demonstrated by Droste et al. ${ }^{25}$

In conclusion, similar to the cases of diabetes and hypertension, treatment options and treatment targets should also be individualized in the case of acromegaly. The complex interplay between $\mathrm{GH} /$ IGF-1 and insulin, together with the reciprocal action on metabolic parameters, should all be taken into consideration when evaluating these patients.

\section{Acknowledgements}

None.

\section{Conflict of interest}

Author declares that there is no conflict of interest.

\section{References}

1. Carvalho D, et al. Clinical experience with somatrem in Growth Hormone deficiency. Acta Paediatr Scand S. 1988;343:240-241

2. Tai PK, Liao JF, Chen EH, et al. Differential regulation of two glucose transporters by chronic growth hormone treatment of cultured 3T\#F442A adipose cells. J Biol Chem. 1990;35:21828-21834.

3. Merimee TJ, Felig P, Marliss E, et al. Glucose and lipid homeostasis in the absence of human growth hormone. J Clin Invest. 1971;50(3):574-582.

4. Bell J, Parker KL, Swinford RD, et al. Long term safety of recombinan human growth hormone in children. $J$ Clin Endocrinol Metab. 2010;95(1):167-177.

5. Svenson J, Fowelin J, Landin K, et al. Effects of seven years on GHreplacement therapy on insulin sensitivity in $\mathrm{G}_{-}$deficient adults. J Clin Endocrinol Metab. 2002;87(5):2121-2127.

6. Oliveira CR, Salvatori R, Barreto-Filho JA, et al. Insulin sensitivity and $\beta$-cell function in adults with lifetime, untreated isolated growth hormone deficiency. J Clin Endocrinol Metab. 2012;97(3):1013-1019.

7. Vicente TA, Rocha IE, Salvatori R, et al. Lifetime congenital isolated GH deficiency does not protect from the development of diabetes. Endocr Connect. 2013;2(2):112-117.

8. Abs R, Mattsson AF, Thunander M, et al. Prevalence of diabetes mellitus in 6050 hypopituitary patients with adult-onset $\mathrm{GH}$ deficiency before $\mathrm{GH}$ replacement: a KIMS analysis. Eur J Endocrinol. 2013;168(3):297-305.
9. Lawrence JH, Tobias CA, Linfoot JA, et al. Successful treatment of acromegaly: metabolic and clinical studies in 145 patients. J Clin Endocrinol Metab. 1970;31(2):180-198.

10. Nogueira C, Carvalho D, Belo S, et al. Glucose metabolism abnormalities in a population of acromegalic patients. Endocrine Abstracts. 2013;32:P632.

11. Mazziotti G, Floriani I, Bonadonna S, et al. Effects of somatostatin analogs on glucose homeostasis: a metaanalysis of acromegaly studies. $J$ Clin Endocrinol Metab. 2009;94(5):1500-1508.

12. Petersenn S, Schopohl J, Barkan A, et al. Pasireotide (SOM230) demonstrates efficacy and safety in patients with acromegaly: a randomized, multicenter, phase II trial. $J$ Clin Endocrinol Metab. 2010;95(6):2781-2789.

13. Colao A, Bronstein MD, Freda $\mathrm{P}$, et al. Pasireotide versus octreotide in acromegaly: a head-to-head superiority study. J Clin Endocrinol Metab. 2014;99(3):791-799.

14. Kumar U, Sasi R, Suresh S, et al. Subtype-selective expression of the five somatostatin receptors (hSSTR1-5) in human pancreatic islet cells: a quantitative double-label immunohistochemical analysis. Diabetes. 1999;48(1):77-85.

15. Zambre $\mathrm{Y}$, Ling $\mathrm{Z}$, Chen $\mathrm{MC}$, et al. Inhibition of human pancreatic islet insulin release by receptor-selective somatostatin analogs directed to somatostatin receptor subtype 5. Biochem Pharmacol. 1999;57(10):1159-1164.

16. Singh V, Brendel MD, Zacharias S, et al. Characterization of somatostatin receptor subtype-specific regulation of insulin and glucagon secretion: an in vitro study on isolated human pancreatic islets. J Clin Endocrinol Metab. 2007;92(2):673-680.

17. Patel YC. Somatostatin and its receptor family. Front Neuroendocrinol. 1999;20(3):157-198.

18. Breitschaft A, Hu K, Resendiz KH, et al. Management of hyperglycemia associated with pasireotide (SOM230): Healthy volunteer study. Diab Res Clin Pract. 2014;103(3):458-465.

19. Drake WM, Rowles SV, Roberts ME, et al. Insulin sensitivity and glucose tolerance improve in patients with acromegaly converted from depot octreotide to pegvisomant. Eur J Endocrinol. 2003;149(6):521-527.

20. Leung KC, Doyle N, Ballesteros M, et al. Insulin regulation of human hepatic growth hormone receptors: divergent effects on biosynthesis and surface translocation. J Clin Endocrinol Metab. 2000;85(12):4712-4720.

21. Neggers SJ, Kopchick JJ, Jorgensen JO, et al. Hypothesis: Extra-hepatic acromegaly: a new paradigm? Eur J Endocrinol. 2011;164(1):11-16.

22. Rubeck KZ, Madsen M, Andreasen CM, et al. Conventional and novel biomarkers of treatment outcome in patients with acromegaly: discordant results after somatostatin analog treatment compared with surgery. Eur $J$ Endocrinol. 2010;163(5):717-726.

23. Flyvbjerg A, Bennett WF, Rasch R, et al. Inhibitory effect of a growth hormone receptor antagonist (G120K-PEG) on renal enlargement, glomerular hypertrophy, and urinary albumin excretion in experimental diabetes in mice. Diabetes. 1999;48(2):377-382.

24. Moller L, Norrelund H, Jessen N, et al. Impact of growth hormone receptor blockade on substrate metabolism during fasting in healthy subjects. J Clin Endocrinol Metabol. 2009;94(11):4524-4532.

25. Droste M, Domberg J, Buchfelder M, et al. Therapy of acromegalic patients exacerbated by concomitant type 2 diabetes requires higher pegvisomant doses to normalise IGF1 levels. EurJ End. 2014;171(1):59-68. 